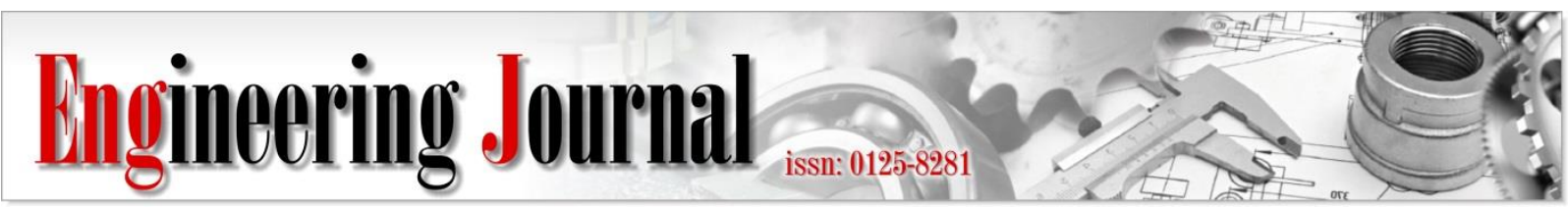

Article

\title{
Nano-Zinc Oxide-Doped Activated Carbon from Popped Rice and Its Application for Feed Additive
}

\author{
Duangporn Saramas ${ }^{1, a}$ and Sanong Ekgasit ${ }^{2, \mathrm{~b}, *}$ \\ 1 Technopreneurship and Innovation Management Program, Graduate School, Chulalongkorn University, \\ Phayathai Road, Pathumwan, Bangkok 10330, Thailand \\ 2 Sensor Research Unit, Department of Chemistry, Faculty of Science, Chulalongkorn University, Phayathai \\ Road, Pathumwan, Bangkok 10330, Thailand \\ E-mail: aduangporn.saramas@gmail.com, b,*sanong.e@chula.ac.th (Corresponding author)
}

\begin{abstract}
This study synthesized nano-zinc oxide $(\mathrm{ZnO})$-doped activated carbon based on popped rice. The rice was prepared by heating unmilled rice using hot air to create a porous structure. The popped rice was chemically activated using zinc chloride $\left(\mathrm{ZnCl}_{2}\right)$ solution at impregnation ratios of $\mathrm{ZnCl}_{2}$ to popped rice (1:1 and 1:2). Pyrolysis was conducted under constant nitrogen flow by raising the temperature at a heating rate of $10^{\circ} \mathrm{C} / \mathrm{min}$ to $800^{\circ} \mathrm{C}$ and maintaining this temperature for $1 \mathrm{~h}$. The adsorption properties of the activated carbon were investigated using methylene blue (MB). The results of ultraviolet-visible spectroscopy (UV-Vis) showed the prepared activated carbon had a high adsorption capacity of MB that could be compared to that of commercial activated carbon. The structure and morphology of the activated carbon containing $\mathrm{ZnO}$ nanoparticles were characterized using raman spectroscopy, field-emission scanning electron microscopy (FESEM), and transmission electron microscopy (TEM)/energy-dispersive spectroscopy (EDS). The specific surface area and porosity were analyzed using the Brunauer-Emmett-Teller (BET) method. The ability to bind 3 different types of mycotoxins was evaluated. The outcome indicates that high surface-area-activated carbon with $\mathrm{ZnO}$ nanoparticles exhibited the potential to bind aflatoxin $\mathrm{B}_{1}$, zearalenone, and fumonisin $\mathrm{B}_{1}$, which could be used as an animal feed additive.
\end{abstract}

Keywords: Popped rice, activated carbon, nano-zinc oxide, feed additive, toxin adsorption.

ENGINEERING JOURNAL Volume 25 Issue 3

Received 27 August 2020

Accepted 21 February 2021

Published 31 March 2021

Online at https://engj.org/

DOI:10.4186/ej.2021.25.3.41 


\section{Introduction}

Rice is one of the major export agricultural products of Thailand. It is the staple food for more than half the world's population and is consumed by over 3.5 billion people worldwide [1]. In particular, Thailand is one of the major exporters of rice in the world rice market. Growing rice has been the way of life for Thai farmers. According to the Thai Rice Exporters Association, Thailand created a record in 2017 by exporting 11.63 million tons of rice [2]. With this, Thailand has become the world's second-largest rice exporter after India.

It should be noted that price fluctuations are common for agricultural products. The price of rice is affected by market volatility, global demand and supply, and natural disasters. Thailand also periodically suffers from the production of low-quality rice, which leads to several problems, such as low-price range, high inventory, and insect-damaged rice. Poor-quality rice fetches lower market prices. Therefore, it is important to find a method to turn inedible low-quality rice into a valuable product.

Rice can be turned into popped rice with a spongelike open pore structure [3]. This unique structure has the potential to be modified into activated carbon due to its outstanding adsorption properties. Activated carbon with high physicochemical stability [4], good mechanical properties [5-6], high surface reactivity [7-8], and a large surface area [9-10] can generally be produced from carbonaceous materials [11] with a well-developed porous structure. Moreover, physical, and chemical properties of the starting materials and activation method play a significant role in the adsorption characteristics of activated carbon $[6,11,12]$. However, activated carbon prepared from starch or grains has not been investigated much compared to activated carbon fibers and granules.

Activated carbon is widely used in a broad range of applications including agriculture [13], environmental remediation [14], energy storage [15], catalysis [16], and electrode materials for electrochemical devices [17]. One interesting application of activated carbon is its use as a mycotoxin binder. Mycotoxins are considered to be one of the most dangerous contaminants of human food and animal feed. Exposure to mycotoxins can result in disease or death in both humans and animals. Global losses due to mycotoxins and their impact on human and animal health have been associated with national economic implications [18]; these losses can occur at all levels of food and feed production, for example, during crop and animal production, processing, and distribution [19]. Among the many mycotoxins that can be found, aflatoxin $\mathrm{B}_{1}$, zearalenone, and fumonisin $\mathrm{B}_{1}$ are well known for their toxicity and occurrence, especially in animals [20-24]. In addition to activated carbon, $\mathrm{ZnO}$ nanoparticles have been used in animal feed as an alternative to existing antibiotics. The addition of $\mathrm{ZnO} \mathrm{n}$ anoparticles to animal feed can increase productivity and effectively reduce the occurrence of postweaning diarrhea in piglets [25].

In this study, activated carbon was prepared by chemically activating popped rice using zinc chloride
$\left(\mathrm{ZnCl}_{2}\right)$. In the absence of an intense washing step, $\mathrm{ZnO}$ remained in the structure of the activated carbon. This method can be an alternative to utilize both activated carbon and $\mathrm{ZnO}$ as feed additives.

The objective of this research was to prepare activated carbon containing $\mathrm{ZnO}$ nanoparticles through a carbonization process using $\mathrm{ZnCl}_{2}$. Low-cost Thai waxy rice was selected as the raw material to prepare the popped rice. The properties of the activated carbon based on popped rice containing $\mathrm{ZnO}$ nanoparticles, including its structure and morphology, were evaluated. Furthermore, the toxin adsorption capacity of activated carbon containing $\mathrm{ZnO}$ nanoparticles was measured.

\section{Experimental}

\subsection{Materials and Chemicals}

A native Thai waxy rice variety with a relatively low commercial value known as "Laow-taek" (Oryza sativa L.) was used as the starting material to produce popped rice. Waxy rice typically has shown very low amylose compared to non-waxy rice which contains high amylose content [26]. Popping of waxy paddy rice in hot air provided higher expansion and higher yield than non-waxy rice [27].

The unmilled rice was taken from the Yasothon Province, which is situated in the northeastern region of Thailand. $\mathrm{ZnCl}_{2}$, (purity $>97 \%$ ) was purchased from Fisher Scientific, whereas ethanol (AR grade) and methylene blue (MB) were purchased from Merck (Thailand). The commercial activated carbon Greater CAR-BON ${ }^{\circledR}$ (Greater Pharma, Thailand) was purchased from a local pharmacy. Standard solutions of aflatoxin $B_{1}$, zearalenone, and fumonisin $\mathrm{B}_{1}$ were purchased from Romer Labs. The chemical structures of aflatoxin $B_{1}$, zearalenone, and fumonisin $\mathrm{B}_{1}$ have been presented in Fig. 1.

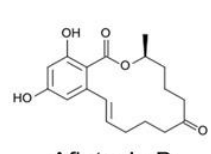

Aflatoxin $\mathrm{B}_{1}$

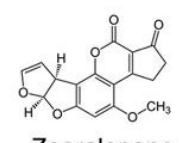

Zearalenone

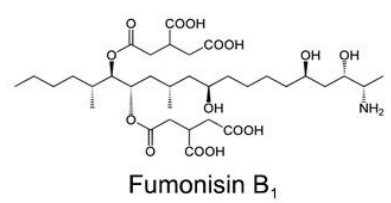

Fumonisin $B_{1}$
Fig. 1. Chemical structures of mycotoxins employed in this study (aflatoxin $\mathrm{B}_{1}$, zearalenone, and fumonisin $\mathrm{B}_{1}$ ).

\subsection{Preparation of Popped Rice and Activated Carbon Samples}

Popping is a simultaneous starch gelatinization and expansion process in which kernels are heated, until the internal moisture expands and pops into the outer shell of the kernel [28-30]. A simple method for making popped rice was performed by the combined mode of conduction and convection heat transfer. The popping process was prepared by hot-air heating at $215^{\circ} \mathrm{C}$. The unmilled rice was popped in an electric pan for 40-60 sec. The amylose and amylopectin in starch granule were 
exploded due to the superheated water in granule. The granule expanded into sponge-like structure. After that, rice husks were removed from popped rice. The popped rice samples were crushed in a blender and sieved to obtain a selected particle size in the range of $1-2 \mathrm{~mm}$. The samples were then dried in an oven at $110^{\circ} \mathrm{C}$ for $3 \mathrm{~h}$ to remove moisture.

As popped rice is hygroscopic material, ethanol was used to prepare $\mathrm{ZnCl}_{2}$ solution at $10 \%$ (w/v). The popped rice was then immersed in $\mathrm{ZnCl}_{2}$ solution at an impregnation ratio of $\mathrm{ZnCl}_{2}$ to popped rice of 1:1 and 1:2. The impregnation time was $24 \mathrm{~h}$ before filtering and drying.

The impregnated samples were subjected to pyrolysis using a muffle furnace under nitrogen gas. A constant nitrogen flow was applied for 20 minutes before pyrolysis to make an oxygen-frees oven. The temperature was continuously raised at a heating rate of $10{ }^{\circ} \mathrm{C} / \mathrm{min}$ to $800{ }^{\circ} \mathrm{C}$. The activation temperature was maintained at $800{ }^{\circ} \mathrm{C}$ for $1 \mathrm{~h}$ before cooling the oven down to ambient temperature.

The activated carbon samples were pulverized by a Rocklabs benchtop ring mill before sieving to achieve a particle size range of $20-45$ microns. In this study, the obtained activated carbons at $\mathrm{ZnCl}_{2}$ impregnation ratio of 1:1 (AZ1), activated carbon at $\mathrm{ZnCl}_{2}$ impregnation ratio of 1:2 (AZ2), commercial activated carbon (CAC), and popped rice carbon without chemical activation (PRC) were then systematically characterized and compared.

\subsection{Characterization}

The adsorption spectra of the prepared carbon samples were collected by a fiber-optic portable UVvisible spectrophotometer (USB4000 UV/visible Spectrometer, Ocean Optics) with a halogen light source (DH-2000, Mikropack). Raman scattering spectra were collected using a DXR f39Raman microscope (ThermoScientific) with a 532-nm excitation laser. The experiments were operated under a 10X objective lens with a laser spot of 50 micrometers. Raman scattering spectra were collected using a 4-second exposure time with 32 accumulations. All spectra were presented without spectral correction. Field-emission scanning electron microscopy (FESEM, JSM-7800F Prime, JEOL) measurements were collected to investigate the morphology of the popped rice and carbon samples using an accelerating voltage of $3 \mathrm{kV}$. All the analyses were conducted using samples that had been gold-coated. The specific surface area and porosity were analyzed using the Brunauer-Emmett-Teller (BET) method with the aid of a nitrogen adsorption-desorption analyzer (BELSORP-mini II, BEL) at $-198^{\circ} \mathrm{C}$. The formation of $\mathrm{ZnO}$ in the activated carbon was analyzed using an X-ray diffractometer (XRD, PANalytical X'Pert PRO) with a $\mathrm{CuK} \alpha(\lambda=1.5406 \AA)$ radiation source operating under a voltage of $40 \mathrm{kV}$ and a current of $30 \mathrm{~mA}$. It should be noted that the diffraction angle $(2 \theta)$ varied between $10^{\circ}$ and $70^{\circ}$ with a step size of $0.02^{\circ}$. Transmission electron microscopy (TEM, JEM 2010F, JEOL) images were collected using an energy-dispersive spectroscopy (EDS) system operating at a working voltage of $200 \mathrm{kV}$.

\subsection{Adsorption Test of Methylene Blue}

The adsorption efficiency has been evaluated by using methylene blue $(\mathrm{MB})$ dye as the adsorbate for investigation. The adsorption experiment was conducted at room temperature using an aqueous solution of $\mathrm{MB}$ at a concentration of $5 \mathrm{ppm}$ and shaking $10 \mathrm{mg}$ of carbon sample in $50 \mathrm{ml}$ of the MB solution. All samples were mixed in a syringe for one minute. Thereafter, the solution was passed through a $5 \mu \mathrm{m}$ Millipore filter paper using a Swinnex ${ }^{\circledR}$ filter holder to connect to the syringe. The removal of $\mathrm{MB}$ was observed with the aid of a UV-Vis spectrophotometer at $666 \mathrm{~nm}$. UV absorbance was measured in a $10-\mathrm{mm}$ cuvette with deionized water as a blank.

\subsection{Mycotoxin Adsorption Test}

An in vitro technique was adopted to simulate the digestion process of pigs [31, 32]. Four samples of carbon were used as adsorbents to validate the in vitro mycotoxin binding test. An enzyme-linked immunosorbent assay (ELISA) was used to analyze aflatoxin $\mathrm{B}_{1}$, zearalenone, and fumonisin $\mathrm{B}_{1}$.

Each sample included a phosphate buffer at $\mathrm{pH}$ 6.0. Then activated carbon samples were added, followed by the diluted mycotoxin standard solution. To simulate the $\mathrm{pH}$ in the stomach, $1.0 \mathrm{M} \mathrm{HCl}$ solution was added to adjust the $\mathrm{pH}$ to a value of 2.0. The mixtures were shaken at $39^{\circ} \mathrm{C}$ for $2 \mathrm{~h}$ in a shaking incubator. Following this, 1 $\mathrm{mL}$ of phosphate buffer $(0.2 \mathrm{M}, \mathrm{pH}$ 6.8) was added to the conical tube. To simulate the conditions in the small intestine, $300 \mu \mathrm{L}$ of $1.0 \mathrm{M} \mathrm{NaOH}$ was added and incubated at $\mathrm{pH} 6.8$ for $4 \mathrm{~h}$. After incubation, the mixture was centrifuged, and the supernatant was collected to analyze the residual unbound toxins. With respect to the blank control, a treatment was prepared without the addition of adsorbents, and incubation was performed under the same conditions, as described earlier.

In this study, ELISA test kits were used to detect the adsorption efficiency of the adsorbent. Three toxins were included: aflatoxin $\mathrm{B}_{1}$, zearalenone, and fumonisin $\mathrm{B}_{1}$. The kits were used to check the amount of unbound mycotoxin. The initial amount of toxin was tested at different levels according to the maximum permissible concentration of each mycotoxin type. The initial amounts of aflatoxin $B_{1}$, zearalenone, and fumonisin $B_{1}$ were 20 ppb, $200 \mathrm{ppb}$, and $1 \mathrm{ppm}$, respectively. The adsorption percentage of activated carbon was calculated by using Eq. (1):

$$
\% \text { adsorption }=\frac{(I M T-U M T)}{I M T} \times 100
$$


where IMT is the initial amount of mycotoxin and UMT refers to the residual amount of unbound mycotoxin after the digestion procedure.

\section{Results and Discussion}

\subsection{UV-Vis Adsorption}

The adsorptive properties were measured by using MB adsorption technique. The test method was adapted from Nardekar and Kale [33]. Figure 2 shows the UV-Vis spectra of all samples for a one-minute adsorption test. The control sample of MB solution without any adsorbate is also included in this figure as a reference. As a result, AZ1 showed the most rapid adsorption of $\mathrm{MB}$ in the initial adsorption, followed by AZ2, CAC, and PRC. It was revealed that the activated carbons using $\mathrm{ZnCl}_{2}$ solution, both AZ1 and AZ2, showed better performance in $\mathrm{MB}$ adsorption than CAC and PRC. AZ1 and AZ2 achieved $88 \%$ and $84 \%$ MB removal, respectively. CAC adsorbed $58 \%$ of $\mathrm{MB}$, whereas PRC only adsorbed $15 \%$ of $\mathrm{MB}$ within one minute.

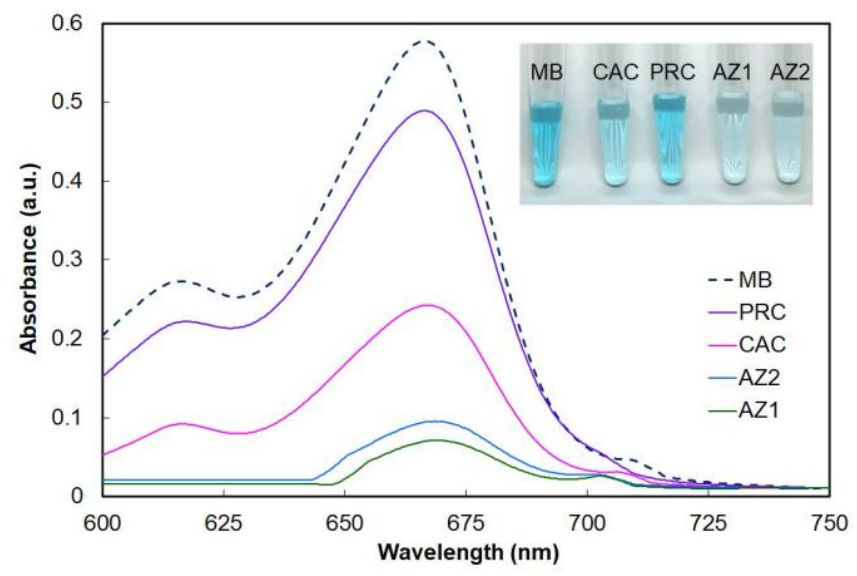

Fig. 2. UV-visible spectra of methylene blue solution after $1 \mathrm{~min}$ adsorption on different carbon samples. The dashed line indicates the control sample of methylene blue.

The faster adsorption rates of AZ1 and AZ2 implied the synergistic effect of activated carbon and $\mathrm{ZnO}$. Principally, activated carbon can adsorb MB molecules due to large surface area, highly developed porosity, good adsorptivity [34]. Compared to CAC and PRC, there is also interaction between $\mathrm{MB}$ and $\mathrm{ZnO}$ shown in $\mathrm{AZ1}$ and AZ2. Since $\mathrm{ZnO}$ demonstrated a high adsorption capacity and fast absorption rate of $\mathrm{MB}$ owing to the ionic bonding between the negatively charged functional groups of $\mathrm{MB}$ (sulfonic groups) and positively charged of $\mathrm{ZnO}$ [35]. As the results, activated carbon containing $\mathrm{ZnO}$ nanoparticles has promising potential applications as effective adsorbents for pollutants as well as toxins.

\subsection{Raman Analysis}

Raman spectroscopy is an important technique for determining chemical characteristic of carbonaceous substances especially carbon black, activated carbon and graphene. The Raman spectra of activated carbon samples are shown in Fig. 3. All spectra are normalized to the intensity of the $G$ band $\left(1560 \mathrm{~cm}^{-1}\right)$ of each spectrum. Two main first-order Raman modes at $1340 \mathrm{~cm}^{-1}$ and $1560 \mathrm{~cm}^{-}$ ${ }^{1}$ were observed for all carbon samples. The $\mathrm{D}$ band at $1340 \mathrm{~cm}^{-1}$ corresponded to disordered carbon, while the $\mathrm{G}$ band at $1560 \mathrm{~cm}^{-1}$ represented graphitized carbon. There were no significant differences in the positions of the $D$ and $G$ bands observed among all samples. The relative intensity of the $G$ band and the $D$ band typically depended on several conditions, including heat treatment, the crystallite size of the disordered carbon, and crystallinity. The intensity ratio of the two first-order D and $\mathrm{G}$ bands is related to the structure of carbon materials [36]. An intensity of the D band lower than that of the $G$ band was found in the Raman spectra of AZ1, AZ2, and PRC. However, the Raman spectra of CAC showed an intensity of the $\mathrm{D}$ band stronger than that of the $\mathrm{G}$ band, illustrated that the disordered carbon atom containing in CAC is higher than AZ1, AZ2, and PRC.

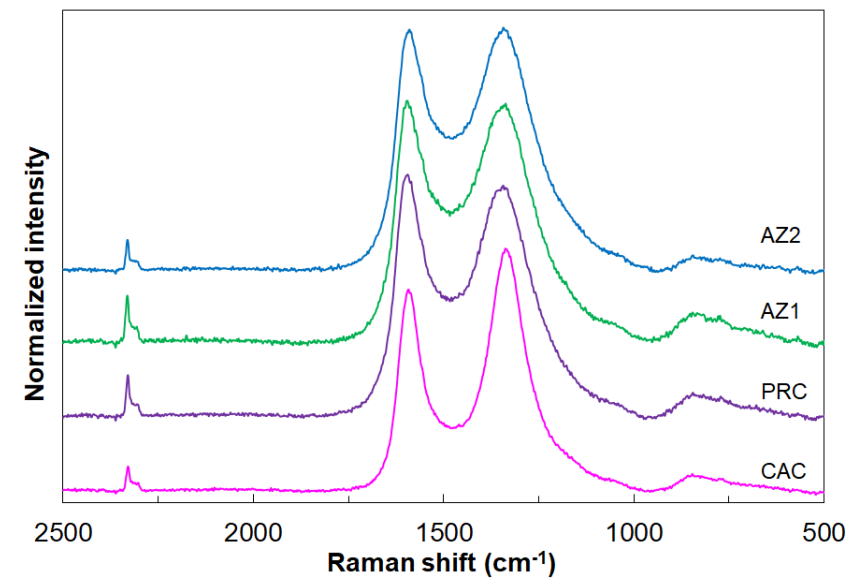

Fig. 3. Normalized Raman spectra of carbon samples from popped rice after pyrolysis and commercial activated carbon.

\subsection{Scanning Electron Microscopy (SEM)}

Scanning electron microscopy (SEM) analysis was used to investigate the surface morphology. The SEM images in Fig. 4 show cross-sections of popped rice. It was confirmed that the morphology of the popped rice developed its porous structure from rice starch granules. The image appears as a sponge-like structure, and a network of pores is created after the popping of unmilled rice grains [3]. For further analysis of the porous structure, carbonization was performed to observe the morphology of the carbon and activated carbon. 


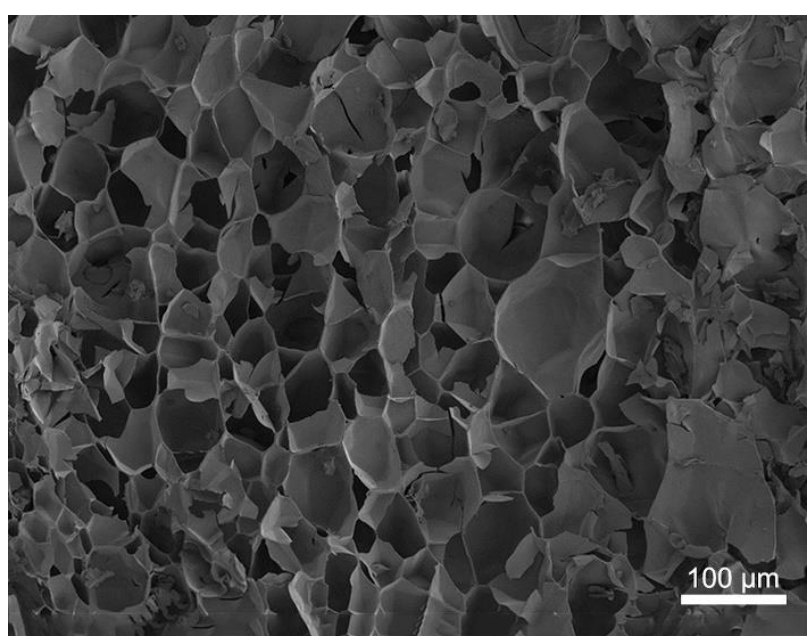

Fig. 4. SEM image showing the porous structure of popped rice before pyrolysis.

The porous structures of all carbon samples were also observed by SEM. The SEM images of CAC, PRC, AZ1, and AZ2 show a porous morphology after pyrolysis (Fig. 5). The surfaces of all samples are magnified 25000 times. The activated carbons, including CAC, AZ1, and AZ2, had a relatively well-developed micropore structure. A large number of micropores were generated as the result of the high surface area and pore volume. Although a porous structure was created in PRC, the structure was composed of large irregular particles, in contrast to CAC, AZ1, and AZ2.
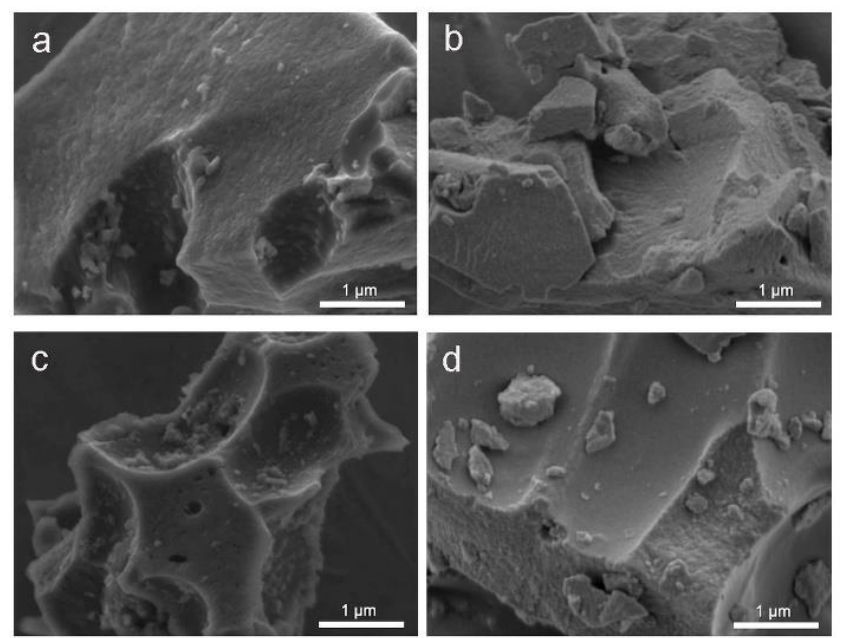

Fig. 5. SEM images of carbon samples from popped rice after pyrolysis and commercial activated carbon: (a) CAC, (b) PRC, (c) AZ1, and (d) AZ2.

\subsection{BET Surface Area}

One of the most important property of carbon-based toxin removal materials is their adsorption capacity, which is directly related to the specific surface area $\left(\mathrm{S}_{\mathrm{BET}}\right)$, the total pore volume $\left(V_{\text {tot }}\right)$, and the micropore volume $\left(V_{\text {mic }}\right)$ of carbon samples. The physicochemical characteristics of the investigated materials are shown in Table 1. CAC showed the highest specific surface area among all the carbon samples, with an $\mathrm{S}_{\text {BET }}$ of $1389.40 \mathrm{~m}^{2} / \mathrm{g}$ and total pore volume $\left(V_{\text {tot }}\right)$ of $0.64 \mathrm{~cm}^{3} / \mathrm{g}$.

Table 1. Physicochemical characteristics of different carbon samples.

\begin{tabular}{cccccc}
\hline Sample & $\begin{array}{c}\mathbf{S}_{\mathrm{BET}} \\
\left(\mathbf{m}^{2} / \mathbf{g}\right)\end{array}$ & $\begin{array}{c}\mathbf{V}_{\text {tot }} \\
\left(\mathbf{c m}^{3} / \mathbf{g}\right)\end{array}$ & $\begin{array}{c}\mathbf{V}_{\text {mic }} \\
\left(\mathrm{cm}^{3} / \mathbf{g}\right)\end{array}$ & $\begin{array}{c}\mathbf{V}_{\text {mic }} / \mathbf{V}_{\text {tot }} \\
(\%)\end{array}$ & $\begin{array}{c}\text { Pore } \\
\text { diameter } \\
(\mathbf{n m})\end{array}$ \\
\hline CAC & 1389.40 & 0.64 & 0.61 & 95.48 & 1.84 \\
PRC & 633.18 & 0.29 & 0.26 & 90.88 & 1.80 \\
AZ1 & 769.50 & 0.36 & 0.33 & 90.61 & 1.88 \\
AZ2 & 553.02 & 0.25 & 0.23 & 90.73 & 1.79 \\
\hline
\end{tabular}

In a previous report, the original popped rice was characterized and found $S_{\mathrm{BET}}$ only $130 \mathrm{~m}^{2} / \mathrm{g}$ [37]. Owing to pyrolysis process, it can be used to transform material to carbon form. The effect of pyrolysis can increase the specific surface area significantly. Pyrolyzed popped rice without $\mathrm{ZnCl}_{2}$ treatment, PRC, showed a developed porous structure with an $\mathrm{S}_{\text {BET }}$ of $633.18 \mathrm{~m}^{2} / \mathrm{g}$ and $\mathrm{V}_{\text {tot }}$ of $0.29 \mathrm{~cm}^{3} / \mathrm{g}$. There is no significant difference in the specific surface area and total pore volume of AZ1 and AZ2 comparing with those of PRC. AZ1 showed an $\mathrm{S}_{\mathrm{BET}}$ of $769.50 \mathrm{~m}^{2} / \mathrm{g}$ and $V_{\text {tot }}$ of $0.36 \mathrm{~cm}^{3} / \mathrm{g}$, while $\mathrm{AZ2}$ presented an $S_{\text {BET }}$ of $553.02 \mathrm{~m}^{2} / \mathrm{g}$ and $V_{\text {tot }}$ of $0.25 \mathrm{~cm}^{3} / \mathrm{g}$. Regarding preparation method, activated carbon samples were prepared without washing to take advantage of $\mathrm{ZnO}$ to enhance the adsorption efficiency. Consequently, $\mathrm{ZnO}$ particles occupied the pores of the activated carbon [39]. The $\mathrm{Zn}$ content contributes to decrease the specific surface area and pore volume of AZ1 and AZ2. The $S_{B E T}$ of $\mathrm{ZnO}$ particles is typically in the range of $10-70 \mathrm{~m}^{2} / \mathrm{g}$ [38] without an obvious porous structure. These $\mathrm{ZnO}$ particles influence the specific surface area and porosity of AZ1 and AZ2. The total pore volumes of CAC, PRC, AZ1, and AZ2 comprised approximately $95.48 \%$, 90.88\%, $90.61 \%$, and $90.73 \%$ of the micropores, respectively. This evidence suggests that all four samples were microporous materials.

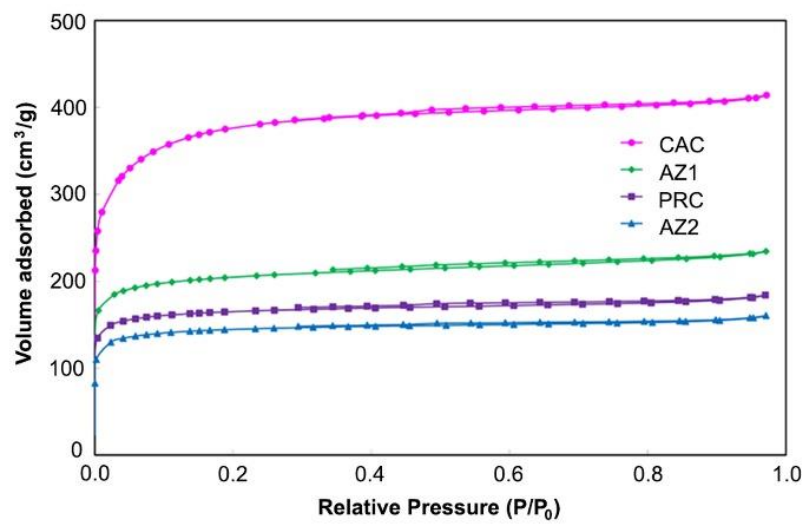

Fig. 6. Adsorption/desorption isotherms of carbon samples from popped rice after pyrolysis and commercial activated carbon. 
The $\mathrm{N}_{2}$ adsorption isotherms of all carbon samples are illustrated in Fig. 6. In accordance with the IUPAC classification, the results show typical Type I isotherms of traditional microporous adsorbents. It is confirmed that micropores compose the majority of the total pores. According to the obtained results, large $\mathrm{S}_{\mathrm{BET}}$ and high micropores can provide evidence of accessibility and utilization of the surface for binding toxins as feed additive purpose.

\subsection{X-Ray Diffraction (XRD)}

The XRD technique is used to study the crystalline nature of materials. Figure 7 shows the XRD patterns of the four samples.

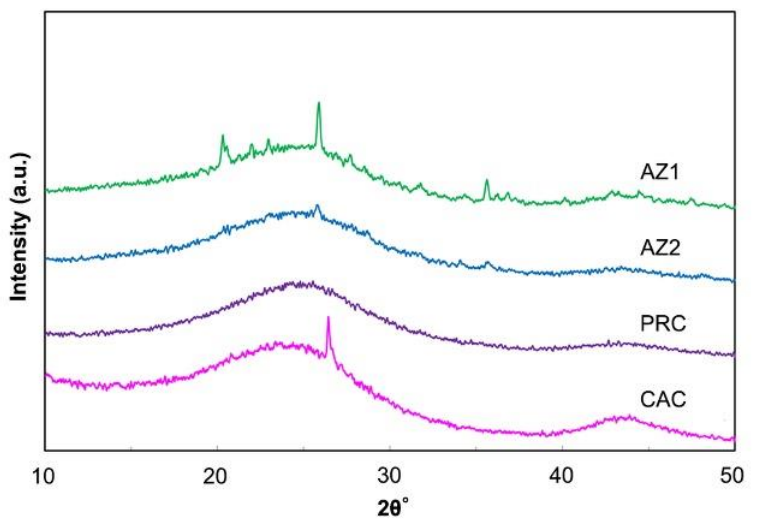

Fig. 7. XRD patterns of carbon samples from popped rice after pyrolysis and commercial activated carbon.

Overall, there are 2 broad peaks at $2 \theta=25.1^{\circ}$ and $45^{\circ}$ related to the (002) and (100) diffractions, respectively. This result indicates the formation of turbostratic structure of disordered carbon [39]. When activation temperature is below $1000{ }^{\circ} \mathrm{C}$, activated carbon is noncrystalline which reveals the predominantly amorphous nature of the carbon [40-41]. Regarding CAC, the sharp narrow peak at $26.1^{\circ}$ indicates the existence of graphitized crystallite in the activated carbon sample [42]. However, PRC shows the absence of a sharp peak compared to CAC The structural identification of the activated carbon containing $\mathrm{ZnO}$ nanoparticles (AZ2 and AZ1) was also determined. The XRD patterns confirm the formation of $\mathrm{ZnO}$ nanoparticles, as seen from the crystallinity. The defined peaks at $31.7,34.4,36.2$, and 47.5 correspond to the (100), (002), (101), and (102) crystal planes of $\mathrm{ZnO}$, respectively. The position of these peaks can confirm the occurrence of the hexagonal wurtzite structure of $\mathrm{ZnO}$, consistent with the values in the standard JCPDS 36-145. Surprisingly, peaks corresponding to zinc magnesium phosphate are also observed the defined peaks at 20.3, $22.0,22.9$, and 25.9 , and 35.7 corresponding to the (101), (101), (111), (210), and (002) crystal planes of zinc magnesium phosphate, respectively. It was determined by comparing the diffraction patterns with the standard JCPDS 31-1468.

\subsection{Transmission Electron Microscopy (TEM)/ Energy-Dispersive Spectroscopy (EDS)}

Transmission electron microscopy (TEM) was carried out on the samples to investigate the zinc nanoparticles. Elemental analysis was performed by EDS attached to the TEM instrument. The TEM images of the zinccompound nanoparticles of PRC, AZ1, and AZ2 have been presented in Fig. 8.

In Fig. 8(a), only $\mathrm{C}$ and $\mathrm{O}$ peaks exist in the PRC sample, except for the peak due to the use of $\mathrm{Cu}$, which was obtained from the copper substrate used for sample examination. In addition, no zinc peaks were detected in the EDS spectrum. From Fig. 8(b) and 8(c), an average particle size of 10-20 nm can be observed. It should be noted that AZ1 showed more zinc nanoparticles than AZ2. The TEM images of the zinc nanoparticles with spherical morphology show that the nanoparticles were uniform and quite monodisperse. Zinc signals were found in the spectra of both AZ1 and AZ2. However, phosphorous peaks were also observed, as this is a common composition in rice paddies [43]. These results indicate that zinc-compound nanoparticles were successfully obtained in AZ1 and AZ2.

\subsection{Toxin Adsorption}

The ability to bind three types of mycotoxin was demonstrated. In general, the binding efficacies of commercially available mycotoxin binders for various mycotoxins are different, varying from $0-90 \%$, with some being more specific to some mycotoxins while some are not $[44,45]$.

The efficiency of adsorbents for binding mycotoxins is not only related to the physical structure, such as the total charge, charge distribution, pore size, and accessible surface area but also depends on several properties of mycotoxins, including polarity, solubility, size, and shape. Moreover, the charge distribution and dissociation are also essential for adsorption [23].

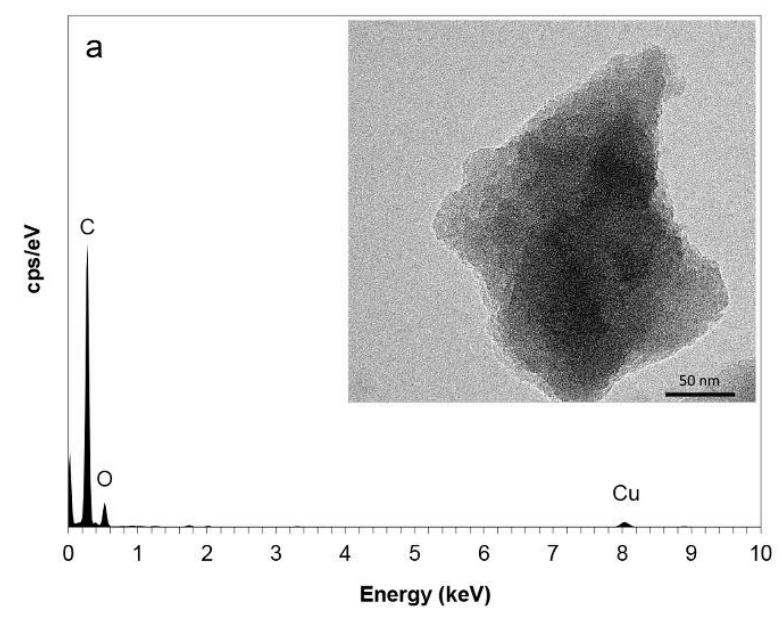



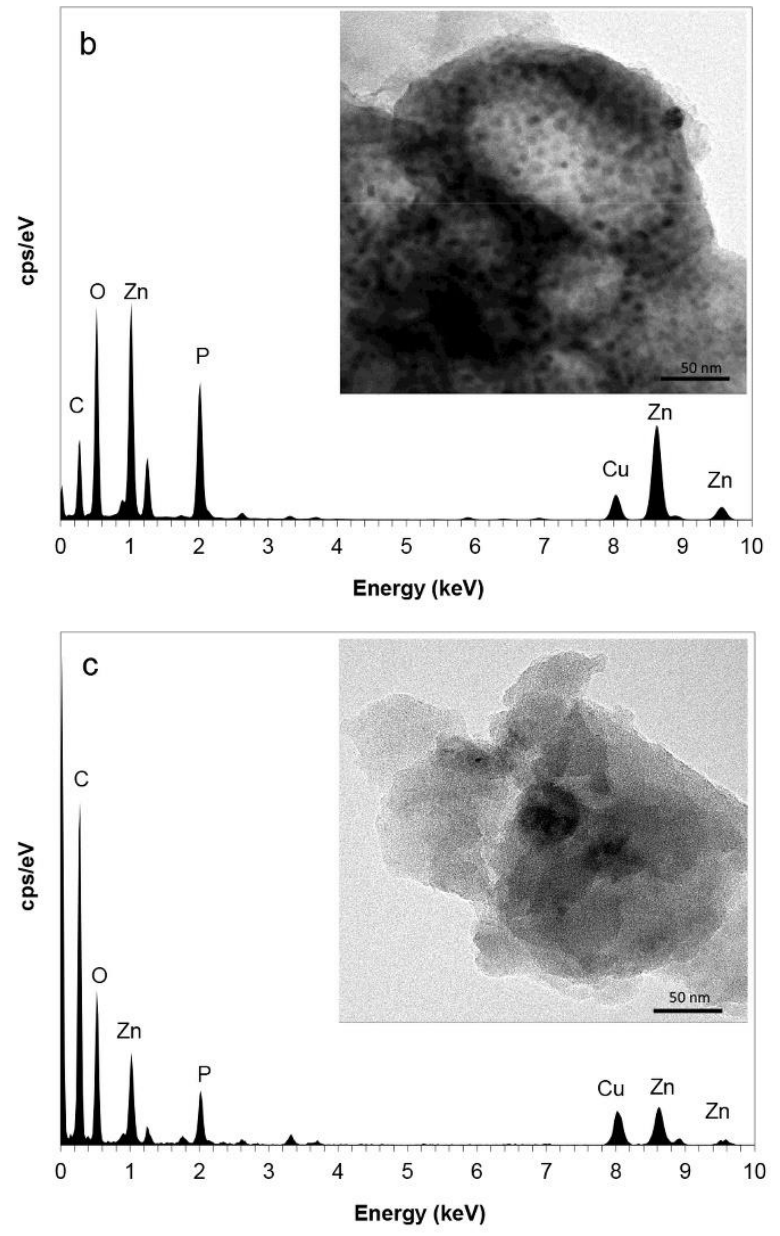

Fig. 8. TEM images of carbon samples (a) PRC show no presence of $\mathrm{ZnO}$ nanoparticles; (b) AZ1 and (c) AZ2 demonstrate the presence of $\mathrm{ZnO}$ nanoparticles.

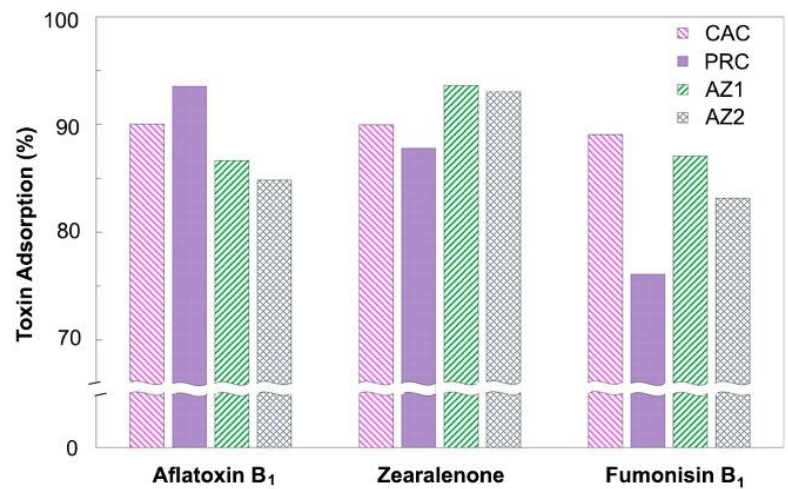

Fig. 9. In vitro adsorption of toxins by CAC, PRC, AZ1, and AZ2.
Since mycotoxins have complex molecular structures, the adsorption capacity depends on various factors. The adsorption percentage of 3 different types of toxin is presented in Fig. 9. The adsorption of aflatoxin $\mathrm{B}_{1}$ by CAC, PRC, AZ1, and AZ2 was $90.02 \%, 93.54 \%, 86.64 \%$, and $84.82 \%$, respectively. All samples were shown to have a high affinity for aflatoxin $\mathrm{B}_{1}$ as they show adsorption efficiencies greater than $80 \%$. Carbon samples were also used for the adsorption of zearalenone. The binding capacities of CAC, PRC, AZ1, and AZ2 were 89.96\%, $87.80 \%, \quad 93.62 \%$, and $93.07 \%$, respectively. The adsorption of fumonisin $\mathrm{B}_{1}$ by CAC, PRC, AZ1, and AZ2 was $89.07 \%, 76.09 \%, 87.06 \%$ and $83.14 \%$, respectively. For the fumonisin $\mathrm{B}_{1}$ adsorption capacity, PRC showed a slightly lower binding capacity than CAC, AZ1, and AZ2. This result should be related to the many polar functional groups in fumonisin $\mathrm{B}_{1}$, as PRC was produced without chemical activation. $\mathrm{ZnCl}_{2}$ was not used to activate for PRC, so there was no Zn complex on the surface of PRC. The experimental adsorption results demonstrate that there was no significant difference among CAC, AZ1, and AZ2, which showed an adsorption capacity is higher than $80 \%$ for all mycotoxin types.

The results have been demonstrated the efficacy of activated carbon to bind aflatoxin B1, zearalenone, and Fumonisin B1. Moreover, $\mathrm{ZnO}$ nanoparticles has been widely used as an alternative to antibiotics in animal feed. The addition of $\mathrm{ZnO}$ nanoparticles can be decreased the incidence of post-weaning diarrhoea in piglets and increased productive performances. The combination of both activated carbon and $\mathrm{ZnO}$ nanoparticles could be potential for using as animal feed additives.

\section{Conclusions}

Activated carbon based on popped rice with the presence of $\mathrm{ZnO}$ nanoparticles was successfully prepared. The prepared activated carbon (AZ1 and AZ2) exhibits a high adsorption capacity of MB compared to that of CAC. The activated carbons, including CAC, AZ1, and AZ2, demonstrated a relatively well-developed microporous structure, composing the majority of the total pores. TEM images, which collected with EDS, verified that spherical Zn nanoparticles were successfully obtained on AZ1 and AZ2. Furthermore, the in vitro experiment shows the potential of the activated carbon samples to bind the three main types of mycotoxin found in Thailand, including aflatoxin $\mathrm{B}_{1}$, zearalenone, and fumonisin $\mathrm{B}_{1}$. Activated carbon based on popped rice with $\mathrm{ZnO}$ nanoparticles shows promising results for use as an animal feed additive.

\section{Acknowledgement}

This research was financially supported by the $90^{\text {th }}$ Anniversary of Chulalongkorn University Scholarship under the Ratchadaphiseksomphot Endowment Fund, Chulalongkorn University (Grant no GCUGR1125611015D). 


\section{References}

[1] S. J. Smyth, P. W. B. Phillips, and D. Castle, Handbook on Agriculture, Biotechnology and Development. Cheltenham, UK: Edward Elgar, 2014.

[2] Thai Rice Exporter Association, "Rice export quantity and value," 2017. [Online]. Available: http://www.thairiceexporters.or.th/statistic_2017.h tml (accessed 10 April 2018)

[3] L. Konharn, "Popping mechanism of popped rice," M.S. thesis, Chulalongkorn Univ., Bangkok, Thailand, 2016.

[4] Z. Zhu, A. Li, S. Zhong, F. Liu, and Q. Zhang, "Preparation and characterization of polymer-based spherical activated carbons with tailored pore structure," J. of Appl. Polym. Sci., vol. 109, no. 3, pp. 1692-1698, Aug. 2008.

[5] S. Guo, J. Peng, W. Li, K. Yang, L. Zhang, S. Zhang, and H. Xia, "Effects of $\mathrm{CO}_{2}$ activation on porous structures of coconut shell-based activated carbons," Appl. Surf. Sci., vol. 255, no. 20, pp. 8443 8449, Jul. 2009.

[6] J. N. Sahu, J. Acharya, and B. C. Meikap, "Optimization of production conditions for activated carbons from Tamarind wood by zinc chloride using response surface methodology," Bioresour. Technol., vol. 101, no. 6, pp. 1974-1982, Mar. 2010.

[7] J. M. Dias, M. C. M. Alvim-Ferraz, M. F. Almeida, J. Rivera-Utrilla, and M. Sánchez-Polo, "Waste materials for activated carbon preparation and its use in aqueous-phase treatment: A review," J. of Environ. Manage., vol. 85, no. 4, pp. 833-846, Jan. 2007.

[8] A. Mohammad-Khah and R. Ansari, "Activated charcoal: Preparation, characterization and applications: a review article," Int. J. Chem. Tech. Res., vol. 1, no. 4, pp. 859-864, Jan. 2009.

[9] Y.-S. Ho, R. Malarvizhi, and N. Sulochana, "Equilibrium isotherm studies of methylene blue adsorption onto activated carbon prepared from Delonix regia pods," J. of Environ. Prot. Sci., vol. 3, pp. 111-116, Jan. 2009.

[10] S. Idris, Y. A. Iyaka, B. E. N. Dauda, M. M. Ndamitso, and M. T. Umar, "Kinetic study of utilizing groundnut shell as an adsorbent in removing chromium and nickel from dye effluent," Chem. Sci. Int. J., vol. 2, no.1, pp. 12-24, Mar. 2012.

[11] D. Cuhadaroglu and O. A. Uygun, "Production and characterization of activated carbon from a bituminous coal by chemical activation," Afr. J. of Biotechnol., vol. 7, no. 20, Oct. 2008.

[12] M. A. Yahya, Z. Al-Qodah, and C. Z. Ngah, "Agricultural bio-waste materials as potential sustainable precursors used for activated carbon production: A review," Renew. Sustain. Energ. Rev., vol. 46, pp. 218-235, Jun. 2015.

[13] L. M. Berglund, T. H. DeLuca, and O. Zackrisson, "Activated carbon amendments to soil alters nitrification rates in Scots pine forests," Soil. Biol. Biochem., vol. 36, no. 12, pp. 2067-2073, Dec. 2004.

[14] T. J. Bandosz, Activated Carbon Surfaces in Environmental Remediation. San Diego, CA: Elsevier, 2006.

[15] R. Madhu, K. V. Sankar, S. M. Chen, and R. K. Selvan, "Eco-friendly synthesis of activated carbon from dead mango leaves for the ultrahigh sensitive detection of toxic heavy metal ions and energy storage applications," RSC Adv., vol. 4, p. 1225, Oct. 2014.

[16] Y. Yang, K.Chiang, and N. Burke, "Porous carbonsupported catalysts for energy and environmental applications: A short review," Catal. Today, vol. 178, no. 1, pp. 197-205, Dec. 2011.

[17] T. Brousse, P.-L. Taberna, O. Crosnier, R. Dugas, P. Guillemet, Y. Scudeller, Y. Zhou, F. Favier, D. Bélanger, and P. Simon, "Long-term cycling behavior of asymmetric activated carbon $/ \mathrm{MnO}_{2}$ aqueous electrochemical supercapacitor," J. of Power Sources, vol. 173, no. 1, pp. 633-641, 2007.

[18] M. E. Zain, "Impact of mycotoxins on humans and animals," J. of Saudi Chem. Soc., vol. 15, no. 2, pp. 129144, 2011.

[19] W. L. Bryden, "Mycotoxin contamination of the feed supply chain: Implications for animal productivity and feed security," Anim. Feed Sci. Technol., vol. 173, no. 1-2, pp. 134-158, 2012.

[20] Council for Agricultural Science and Technology, Mycotoxins: Economic and Health Risks. Ames, IA: CAST, 1989.

[21] M. Adams and Y. Motarjemi, Basic Food Safety for Health Workers, Geneva: Switzerland: WHO, 1999.

[22] F. Galvano, A. Piva, A. Ritieni, and G. Galvano, "Dietary strategies to counteract the effects of mycotoxins: a review," J. Food Prot., vol. 64, no. 1, pp. 120-131, 2001.

[23] N. H. Phuong, N. Q. Thieu, B. Ogle, and H. Pettersson, "Aflatoxins, fumonisins and zearalenone contamination of maize in the southeastern and central highlands provinces of Vietnam," Agriculture, vol. 5, no. 4, pp. 1195-1203, 2015.

[24] A. Kolosova and J. Stroka, "Substances for reduction of the contamination of feed by mycotoxins: A review," World Mycotoxin J., vol. 4, no. 3, pp. 225-256, 2011.

[25] R. Raguvaran, A. Manuja, and B. K. Manuja, "Zinc oxide nanoparticles: Opportunities and challenges in veterinary sciences," Immunome Res, vol. 11, no. 2, 2015.

[26] S. Maisont and W. Narkrugsa, "Effects of some physicochemical properties of paddy rice varieties on puffing qualities by microwave "ORIGINAL". Agric. Nat. Resour., vol. 43, no. 3, pp. 566-575, 2009.

[27] M. Simsrisakul, "Important factors affecting puffing quality of paddy and properties of puffed rice flour". 
M.S. Thesis. Chulalongkorn University. Bangkok, Thailand, 1991.

[28] A. Arkhipov, C. Becker, D. Bergamo, V. Demtchouk, A. M. Freddo, E. Kreider, M. Lee, J. Montalbano, D. Richards, E. So, J. Wang, P. Quinn, and S. Warner, "Popping under pressure: The physics ofpopcorn,” 2005. Available: https://depts.drew.edu/

govschl/NJGSS2005/Journal/TeamPapers/T3_Po pcorn.pdf

[29] C. Solanki, N. Indore, D. Mridula, and K. Nanda, "Microwave vs conventional popping system: A comparative evaluation for maize popping," Int. J. Chem. Stud., vol. 6, no. 6, pp. 176-181, 2018.

[30] G. Mishra, D. C. Joshi, and B. K. Panda, "Popping and puffing of cereal grains: A review," J. grain processing storage, vol. 1, no. 2, pp. 34-46, 2014.

[31] C. Kong, S. Y. Shin, and B. G. Kim, "Evaluation of mycotoxin sequestering agents for aflatoxin and deoxynivalenol: An in vitro approach," SpringerPlus, vol. 3, no. 1, pp. 346, 2014.

[32] S. Boisen and J. A. Fernández, "Prediction of the total tract digestibility of energy in feedstuffs and pig diets by in vitro analyses," Anim. Feed Sci. Technol., vol. 68, no. 3-4, pp. 277-286, 1997.

[33] S. S. Nardekar and R. D. Kale, "Degradation of methylene blue dye using activated carbon obtained from bio-waste," Int.j. res. appl. sci. eng. technol., Vol. 5, no. 11, pp. 2050-2054, 2017.

[34] F. Zhang, J. Lan, Y. Yang, T. Wei, R. Tan, and W. Song, "Adsorption behavior and mechanism of methyl blue on zinc oxide nanoparticles," J. Nanopart. Res., vol. 15, no. 11, pp. 2034, 2013.

[35] M. J. Iqbal and M. N. Ashiq, "Adsorption of dyes from aqueous solutions on activated charcoal," $J$. Hazard. Mat., vol. 139, no. 1, pp. 57-66, 2007.

[36] P. Lespade, R. Al-Jishi, and M. S. Dresselhaus, "Model for Raman scattering from incompletely graphitized carbons," Carbon, vol. 20, no. 5, pp. $427-$ 431, 1982.

[37] P. Nisawa-Anutaraphan, "Preparation of activated carbon from rice via microwave-induced $\mathrm{ZnCl}_{2}$ activation," M.S. Thesis. Chulalongkorn University. Bangkok, Thailand, 2018.

[38] A. Kolosova and J. Stroka, "Substances for reduction of the contamination of feed by mycotoxins: A review," World Mycotoxin J., vol. 4, no. 3, pp. 225-256, 2011.

[39] T. H. Liou, "Development of mesoporous structure and high adsorption capacity of biomass-based activated carbon by phosphoric acid and zinc chloride activation," Chem. Eng. J., vol. 158, no. 2, pp. 129-142, 2010.

[40] J. Zhao, L. Yang, F. Li, R. Yu, and C. Jin, "Structural evolution in the graphitization process of activated carbon by high-pressure sintering," Carbon, vol. 47, no. 3, pp. 744-751, 2009.

[41] J. Xu, L. Chen, H. Qu, Y. Jiao, J. Xie, and G. Xing, "Preparation and characterization of activated carbon from reedy grass leaves by chemical activation with $\mathrm{H}_{3} \mathrm{PO}_{4}$," Appl. Surf. Sci., vol. 320, pp. 674-680, 2014.

[42] A. Dandekar, R. T. K. Baker, and M. A. Vannice, "Characterization of activated carbon, graphitized carbon fibers and synthetic diamond powder using TPD and DRIFTS," Carbon, vol. 36, no. 12, pp. 1821-1831, 1998.

[43] F. Wang, T. Rose, K. Jeong, T. Kretzschmar, and M. Wissuwa, "The knowns and unknowns of phosphorus loading into grains, and implications for phosphorus efficiency in cropping systems," J. Exp. Bot., vol. 67, no. 5, pp. 1221-1229, 2016.

[44] A. Huwig, S. Freimund, O. Käppeli, and H. Dutler, "Mycotoxin detoxication of animal feed by different adsorbents," Toxicology Lett., vol. 122, no. 2, pp. 179188, 2001.

[45] K. A. Dawson, J. E. F. F. Evans, and M. Kudupoje, "Understanding the adsorption characteristics of yeast cell wall preparations associated with mycotoxin binding," in Science and Technology in the Feed Industry. Nottingham University Press: Nottingham, UK, pp. 169-181, 2001.

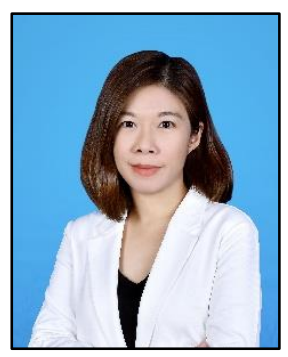

Duangporn Saramas was born in Bangkok, Thailand, in 1980. She received her B.Eng. degree in Chemical Engineering from King Mongkut's University of Technology Thonburi. She received her M.Sc. degree in Polymer Science from The Petroleum and Petrochemical College, Chulalongkorn University, and M.M. degree in Management and Strategy from The College of Management, Mahidol University. Dr. Saramas obtained her Ph.D. degree in Technopreneurship and Innovation Management Program from Graduate School, Chulalongkorn University.

She has worked in the petrochemical business with experience in several functions including product development, customer technical service, marketing, and sales. Her research interests include nanomaterials, polymer composites/nanocomposites, and polymer processing. 


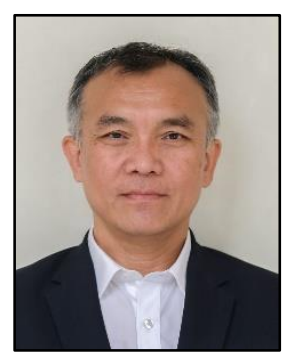

Sanong Ekgasit received his B.Sc. degree in Chemistry and M.Eng. degree in Polymer Technology, in 1989 and 1992, respectively from Chulalongkorn University, Thailand. He received Ph.D. in Polymer Science and Engineering from Case Western Reserve University, USA in 1996. He has been working at Department of Chemistry, Faculty of Science, Chulalongkorn University since 1999. His research interests include molecular spectroscopy, nanomaterials (synthesis, modification, and commercialization) cellulose nanocrystals (synthesis and applications), and Lab-on-Phone researches.

Professor Dr. Sanong Ekgasit was a recipent of National Outstanding Researcher Award in 2008, The National Excellent Researchers Awards in 2012, and CST Award for Distinguished Contribution to Economic Advancement in 2016. 